\title{
Prognostic Value of Fibrinogen in Patients With Coronary Artery Disease and Prediabetes or Diabetes Following Percutaneous Coronary Intervention: Five-year Findings From a Large Cohort Study
}

\section{Deshan Yuan}

Chinese Academy of Medical Sciences \& Peking Union Medical College Fuwai Hospital

\section{Ping Jiang}

Chinese Academy of Medical Sciences \& Peking Union Medical College Fuwai Hospital

Pei Zhu

Chinese Academy of Medical Sciences \& Peking Union Medical College Fuwai Hospital

\section{Sida Jia}

Chinese Academy of Medical Sciences \& Peking Union Medical College Fuwai Hospital

\section{Ce Zhang}

Chinese Academy of Medical Sciences \& Peking Union Medical College Fuwai Hospital Yue Liu

Chinese Academy of Medical Sciences \& Peking Union Medical College Fuwai Hospital Ru Liu

Chinese Academy of Medical Sciences \& Peking Union Medical College Fuwai Hospital Jingjing Xu

Chinese Academy of Medical Sciences \& Peking Union Medical College Fuwai Hospital

\section{Xiaofang Tang}

Chinese Academy of Medical Sciences \& Peking Union Medical College Fuwai Hospital

\section{Xueyan Zhao}

Chinese Academy of Medical Sciences \& Peking Union Medical College Fuwai Hospital

\section{Runlin Gao}

Chinese Academy of Medical Sciences \& Peking Union Medical College Fuwai Hospital

\section{Yuejin Yang}

Chinese Academy of Medical Sciences \& Peking Union Medical College Fuwai Hospital

\section{Bo Xu}

Chinese Academy of Medical Sciences \& Peking Union Medical College Fuwai Hospital

\section{Zhan Gao}

Chinese Academy of Medical Sciences \& Peking Union Medical College Fuwai Hospital 
Jinqing Yuan ( $\nabla$ dr_jinqingyuan@sina.com )

Chinese Academy of Medical Sciences and Peking Union Medical College Fuwai Hospital https://orcid.org/0000-0003-0284-1236

\section{Original investigation}

Keywords: Fibrinogen, Coronary artery disease, Percutaneous coronary intervention, Prediabetes, diabetes

Posted Date: April 21st, 2021

DOl: https://doi.org/10.21203/rs.3.rs-435818/v1

License: (c) (1) This work is licensed under a Creative Commons Attribution 4.0 International License. Read Full License

Version of Record: A version of this preprint was published at Cardiovascular Diabetology on July 16th, 2021. See the published version at https://doi.org/10.1186/s12933-021-01335-1. 


\section{Abstract}

Background: Fibrinogen (FIB) is an independent risk factor for mortality and cardiovascular events in the general population. However, the relationship between FIB and long-term mortality among CAD patients undergoing $\mathrm{PCl}$ remains unclear, especially in individuals complicated with diabetes mellitus (DM) or prediabetes (Pre-DM).

Methods: 6,140 patients with CAD undergoing PCl were included in the study and subsequently divided into three groups according to FIB levels (FIB-L, FIB-M, FIB-H). These patients were further grouped by glycemic status [normoglycemia (NG), Pre-DM, DM]. The primary endpoint was all-cause mortality. The secondary endpoint was cardiac mortality.

Results: FIB was positively associated with hemoglobin A1c (HbA1c) and fasting blood glucose (FBG) in CAD patients with and without DM $(P<0.001)$. During a median follow-up of 5.1 years, elevated FIB was significantly associated with long-term all-cause mortality (adjusted HR: 1.86; 95\% Cl: 1.28-2.69; P=0.001) and cardiac mortality (adjusted HR: 1.82; 95\% Cl: 1.15-2.89; $\mathrm{P}=0.011$ ). Similarly, patients with $\mathrm{DM}$, but not Pre-DM, had increased risk of all-cause and cardiac mortality compared with NG group (all $P<0.05$ ). When grouped by both FIB levels and glycemic status, diabetic patients with medium and high FIB levels had higher risk of mortality [(adjusted HR: 2.57; 95\% Cl: 1.12-5.89), (adjusted HR: 3.04; 95\% Cl: 1.35-6.82), all $\mathrm{P}<0.05]$. Notably, prediabetic patients with high FIB also had higher mortality risk (adjusted HR: 2.27; 95\% Cl: 1.01-5.12).

Conclusions: FIB was strongly associated with long-term all-cause and cardiac mortality among CAD patients undergoing $\mathrm{PCl}$, especially in those with DM and Pre-DM. FIB test may help to identify high-risk individuals in this specific population.

\section{Background}

Despite advances in revascularization strategies over recent decades, the clinical outcomes remain unfavorable in patients with coronary artery disease (CAD), especially when complicated with diabetes mellitus (DM)[1]. Regarded as a pivotal component of coagulation as well as a biomarker of inflammation, fibrinogen (FIB) plays a crucial role in the pathophysiological process of thrombosis and atherosclerosis[2-5]. Previous evidences suggested that FIB was an independent risk factor of CAD development and cardiovascular events in the general population[6, 7]. Similar results on the prognostic value of FIB were also observed in patients with CAD[8-10].

Glycemic metabolism abnormality, including DM and prediabetes (pre-DM), is increasingly prevalent on a global scale. By 2045, over 600 million individuals are projected to develop DM, with about the same number developing pre-DM[11]. The cardiovascular disease (CVD) risk, disability and mortality brought by glycemic metabolism abnormality is undisputedly a serious public health concern. Interestingly, FIB level was found to be higher in diabetic and prediabetic patients, and was involved in glycemic metabolism abnormality and insulin resistance[12, 13]. Moreover, recent studies reported that FIB was positively 
related with the glycemic metabolism (hemoglobin $\mathrm{A} 1 \mathrm{c}[\mathrm{HbA} 1 \mathrm{c}]$ and fasting blood glucose [FBG]) in patients with acute coronary syndrome (ACS) or stable CAD $[9,10]$. However, few data are available examining the correlation between FIB and glycemic metabolism in CAD patients undergoing percutaneous coronary intervention (PCI). Furthermore, the association of FIB with long-term outcomes in this population was far less investigated, particularly in those with impaired glycemic metabolism.

In light of the above, we aimed to evaluate the relationship between FIB and glycemic metabolism, and further determine the combined effect of FIB and impaired glycemic metabolism on long-term all-cause and cardiac mortality in CAD patients undergoing $\mathrm{PCl}$.

\section{Methods}

\section{Study population}

This study was based on a prospective, observational, single-center cohort. From January 2013 to December 2013, 10,724 CAD patients were consecutively enrolled undergoing PCl at Fuwai Hospital, Chinese Academy of Medical Sciences (Beijing, China) (Figure 1). Patients with missing FIB $(n=4,278)$ and Low-density lipoprotein cholesterol $(n=153)$ values were excluded. A total of 6,140 patients were ultimately included in the analysis. The study protocol was approved by the Institutional Review Board of Fuwai Hospital and complied with the Declaration of Helsinki. All patients provided written informed consent before the intervention. Regular follow-up assessment of patients was performed at five time points (1-month, 6-month, 12-month, 2-year, and 5-year after the discharge). Follow-up data were collected through medical records and telephone interview. The primary endpoint was all-cause mortality. The secondary outcome was cardiac mortality. Mortality that could not be attributed to a noncardiac etiology was considered cardiac mortality. All endpoints were adjudicated centrally by 2 independent cardiologists, and disagreement was resolved by consensus.

\section{Procedure and medications}

Before the procedure, patients receiving selective $\mathrm{PCl}$ were treated with aspirin (300mg) and ticagrelor (loading dose, 180mg) or clopidogrel (loading dose, 300mg), except for patients already on dual antiplatelet therapy; for patients with ACS receiving emergency $\mathrm{PCl}$, the same dose of aspirin and ticagrelor or clopidogrel (loading dose, 300-600 mg) were administered as soon as possible. All patients were administered with unfractionated heparin $(100 \mathrm{U} / \mathrm{kg})$, and interventional cardiologist decided whether to use glycoprotein Ilb/Illa antagonist according to the clinical conditions and coronary lesions during the procedure. After the procedure, the dual antiplatelet therapy including aspirin (100mg daily), ticagrelor ( $90 \mathrm{mg}$, twice daily) or clopidogrel $(75 \mathrm{mg}$, daily) were recommended for at least 1 year. The choice of equipment and techniques during $\mathrm{PCl}$ was at the discretion of the physicians.

\section{Definition of clinical status}


Glycemic categories were based on the guideline recommendations of American Diabetes Association[14]. Diabetes mellitus (DM) was defined by HbA1c levels $\geq 6.5 \%$, or fasting blood glucose (FBG) $\geq 7.0 \mathrm{mmol} / \mathrm{L}$, or 2-hour blood glucose levels of oral glucose tolerance test $\geq 11.1 \mathrm{mmol} / \mathrm{L}$ ), or current use of hypoglycemic medications. Prediabetes (Pre-DM) was defined as nondiabetic patients with FBG ranging from 5.6 to $6.9 \mathrm{mmol} / \mathrm{L}, \mathrm{HbA} 1 \mathrm{c}$ levels ranging from $5.7 \%$ to $6.4 \%$. Patients without Pre-DM or DM were defined as normoglycemia (NG). Hypertension was defined as systolic blood pressure $\geq 140$ $\mathrm{mmHg}$ and/or diastolic blood pressure $\geq 90 \mathrm{mmHg}$ and/or current use of antihypertensive drugs. Lowdensity lipoprotein cholesterol $\geq 3.4 \mathrm{mmol} / \mathrm{L}$, fasting total cholesterol $\geq 5.2 \mathrm{mmol} / \mathrm{L}$, triglyceride $\geq 1.7$ $\mathrm{mmol} / \mathrm{L}$, high-density lipoprotein cholesterol $<1.0 \mathrm{mmol} / \mathrm{L}$ and/or chronic use of lipid-lowering drugs were considered criteria for dyslipidemia. Left main disease was defined as stenosis of $\geq 50 \%$ in left main coronary artery, and three-vessel disease was defined as stenosis of $\geq 50 \%$ in all three main coronary arteries (right coronary artery, left circumflex artery and left anterior descending artery) confirmed by coronary angiography.

\section{Laboratory analysis}

Fasting blood samples were drawn from all patients within 24 hours after admission. Enzymatic hexokinase method was used to measure the concentrations of blood glucose. Tosoh Automated Glycohemoglobin Analyzer (HLC-723G8) was used to measure the HbA1c levels. Stago autoanalyzer with the STA fibrinogen kit (Diagnostica Stago, Taverny, France) was used to measure the concentrations of FIB. All other laboratory measurements were conducted at the biochemistry center of Fu Wai Hospital by standard biochemical techniques.

\section{Statistical analysis}

Continuous variables were presented as mean \pm standard deviation, while categorical variables were presented as frequency and percentage. Differences of continuous and categorical variables were analyzed by analysis of variance or Kruskal-Wallis test and c2 test or Fisher's exact test, as appropriate. Linear regression analysis was performed to evaluate the correlation between FIB and glycemic metabolism (HbA1c and FBG). In survival analysis, the association between FIB and clinical endpoint was initially examined using restricted cubic splines. The FIB was subsequently analyzed as both a continuous and a categorical variable. For categorical analysis, patients were grouped according to tertiles of the distribution [FIB-L(<2.98mg/dL), FIB-M(2.98-3.59mg/dL), FIB-H( $<3.59 \mathrm{mg} / \mathrm{dL})$ ]. Survival distributions were presented by Kaplan-Meier curves and compared by log-rank test. Cox regression analyses were performed to calculate the hazard ratios (HRs) and $95 \%$ confidence interval (Cl). Proportional hazards assumption was verified by Schoenfeld residuals. In multivariate Cox analyses, covariates including age, sex, body mass index (BMI), hypertension, family history of CAD, prior $\mathrm{PCI} / \mathrm{CABG}$, LVEF, LDL-C, creatine, DES implantation, clopidogrel, ACEI/ARB were adjusted because of their statistical significance in univariate analysis or clinical importance. The prognostic impact of glycemic metabolism status (NG, Pre-DM and DM) for all-cause mortality was also assessed by using the model mentioned above. Patients were further divided into 9 groups by both FIB levels and glycemic metabolism 
status to calculate HRs for all-cause mortality using FIB-L plus NG as reference. Statistical analyses were conducted with SPSS version 25.0 (IBM Corp., Armonk, N.Y., USA), R Programming Language version 4.0.0 (R Core Team, 2014), and GraphPad Prism version 7.0.0 for windows (GraphPad Software, San Diego, California USA). A two-tailed $P$ value $<0.05$ was considered statistically significant.

\section{Results}

\section{Baseline characteristics of patients with different FIB levels}

Among the 6140 patients, the mean age was $58.4 \pm 10.4$ years, and $4771(77.7 \%)$ were male. The baseline characteristics of patients according to the tertiles of FIB are summarized in Table 1. Patients with higher FIB levels were older and less likely to be male (all $P<0.05$ ). In addition, they had higher proportion of diabetes, hypertension, prior stroke, ACS, and left main or three-vessel disease (all $\mathrm{P}<0.05$ ). Moreover, patients with elevated FIB levels had higher FBG, HbA1c, TC, LDL cholesterol, creatinine, lesion vessels, SYNTAX score, but lower LVEF and lower rate of complete revascularization (all $P<0.05$ ). No significant differences were noted regarding dyslipidemia, family history of CAD, smoking, HDL cholesterol, number of stents and DES implantation among these groups (all $P>0.05$ ).

\section{Comparison of clinical data among groups with different glycemic metabolism status}

In Table 2, Patients were divided into three subgroups based on different glycemic metabolism status. In general, the DM and pre-DM group had a less favorable cardiovascular risk profile. Patients with DM or pre-DM tended to be older and female, with a larger burden of concomitant diseases, such as hypertension, dyslipidemia and prior stroke compared with those in NG group (all $\mathrm{P}<0.05$ ). Additionally, the prevalence of prior PCI/CABG and left main or three-vessel disease was higher in the DM and pre-DM group (all $\mathrm{P}<0.05$ ). Meanwhile, there were also higher $\mathrm{BMI}, \mathrm{FBG}, \mathrm{HbA1c}, \mathrm{TG}$, number of diseased vessels, SYNTAX score, number of stents, and lower LVEF, HDL cholesterol, complete revascularization, DES implantation in the DM group (all $P<0.05$ ). Notably, FIB levels were significantly elevated from NG to DM group $(P<0.001)$.

\section{Relationship between HbA1c/FBG and FIB}

Linear regression analysis was used to assess the correlation between glycemic metabolism and FIB (Table 3). The results showed that both admission HbA1c $\left(R^{2}=0.018\right.$, Standard $\left.\beta=0.133, P<0.001\right)$ and FBG $\left(R^{2}=0.012\right.$, Standard $\left.\beta=0.111, P<0.001\right)$ were positively associated with FIB in the whole cohort. In DM patients, HbA1c $\left(R^{2}=0.026\right.$, Standard $\left.\beta=0.163, P<0.001\right)$ and FBG $\left(R^{2}=0.012\right.$, Standard $\beta=0.111, P<0.001)$ were also positively associated with FIB. Furthermore, this positive relationship between HbA1c $\left(R^{2}=0.012\right.$, Standard $\left.\beta=0.111, P<0.001\right)$ and FBG $\left(R^{2}=0.009\right.$, Standard $\left.\beta=0.096, P<0.001\right)$ with FIB remained significant in the non-DM patients (Figure 2).

\section{Predictive value of FIB on all-cause mortality and cardiac mortality}


The median follow-up time was 5.1 years (interquartile range 5.0-5.2 years), and the response rate was 91.2\% (Figure 1). During this period, 214 (3.5\%) patients experienced all-cause mortality, of which 127 was cardiac mortality (accounted for 58.5\%). The incidence of all-cause mortality in FIB-L, FIB-M and FIB$\mathrm{H}$ group was $2.1 \%, 3.7 \%$ and $4.7 \%$, respectively. Restricted cubic splines visualized a positive relation between FIB on a continuous scale with long-term risk of all-cause mortality and cardiac mortality (all P for non-linearity $>0.05$ ) (Additional file 1:Figure S1). The Kaplan-Meier survival curve revealed that patients with higher FIB levels had significantly increased risk of all-cause mortality and cardiac mortality (all logrank $\mathrm{P}<0.001$ ) (Figure 3a, Additional file 1: Figure S2a). The univariate Cox analysis showed a strong relation between continuous FIB with all-cause mortality (HR: 1.36; $95 \% \mathrm{Cl}: 1.20-1.55$ per 1 unit increase in FIB; $\mathrm{P}<0.001$ ) and cardiac mortality (HR: $1.46 ; 95 \%$ Cl: $1.25-1.71$ per 1 unit increase in FIB; $P<0.001)$. On multivariate analysis, the relationship between continuous as well as tertiles of FIB with all-cause mortality (adjusted HR: 1.23; 95\% Cl: 1.07-1.42 per 1 unit increase in FIB; $P=0.004$ ) and cardiac mortality (adjusted HR: $1.31 ; 95 \% \mathrm{Cl}: 1.10-1.55$ per 1 unit increase in $\mathrm{FIB} ; \mathrm{P}=0.003$ ) remained statistically significant after adjustment for potential confounders (Table 4).

\section{Glycemic metabolism, FIB levels and occurrence of all-cause mortality}

The prevalence of all-cause mortality in NG, Pre-DM and DM group was $2.4 \%, 3.3 \%$ and $4.6 \%$, respectively. The Kaplan-Meier curve demonstrated that patients with DM had significantly increased risk of all-cause mortality and cardiac mortality among the three groups (all log-rank $\mathrm{P}<0.05$ ) (Figure 3b, Additional file 1: Figure S2b). Univariate Cox analysis revealed that DM group had 1.91-fold higher risk of all-cause mortality (HR: 1.91; 95\% Cl: 1.28-2.84; $\mathrm{P}=0.001)$ and 2.18-fold higher risk of cardiac mortality (HR: 2.18; $95 \% \mathrm{Cl}: 1.28-3.37 ; \mathrm{P}=0.004)$ when compared with NG group. And this significant association remained unchanged after adjustment for other covariates. However, Pre-DM group did not increase the risk of allcause mortality and cardiac mortality compared with NG group (Figure 4, Additional file 1: Figure S3).

When patients were evaluated according to both glycemic metabolism and FIB levels, the Kaplan-Meier curve showed that those with DM and FIB-H levels had significantly highest risk of all-cause mortality compared with the reference group (NG plus FIB-L group, log rank $\mathrm{P}<0.001$ ). Furthermore, NG plus FIB-H, Pre-DM plus FIB-M, Pre-DM plus FIB-H and DM plus FIB-M groups also had significantly increased risk of all-cause mortality than the reference group (NG plus FIB-L group, all log rank $\mathrm{P}<0.05$ ) (Figure 3c). The further univariate Cox analysis revealed similar results. Multivariate Cox analysis according to both glycemic metabolism and FIB levels indicated that patients in Pre-DM plus FIB-H, DM plus FIB-M and DM plus FIB-H groups had 2.27-fold (adjusted HR: 2.27; 95\% Cl: 1.01-5.12), 2.57-fold (adjusted HR: 2.57; 95\% Cl: 1.12-5.89) and 3.04-fold (adjusted HR: 3.04; 95\% Cl: 1.35-6.82) higher risk of all-cause mortality, respectively (all $\mathrm{P}<0.05)$ (Table 5).

\section{Discussion}

Using a large, real-world, prospective cohort sample, we found that FIB positively correlated with glycemic metabolism in CAD patients undergoing PCI. Moreover, higher FIB levels, analyzed as continuous or 
categorical variables, were strongly associated with increased risk of long-term all-cause and cardiac mortality. Furthermore, poorer long-term outcomes were also found in diabetic patients, but not in prediabetic patients. Interestingly, when patients were categorized into 9 groups according to both FIB levels and glycemic metabolism status, patients with pre-DM plus high FIB levels, DM plus medium FIB levels and DM plus high FIB levels had increased risk of all-cause mortality than those with NG and low FIB levels. For the first time, our study demonstrated that FIB might affect the long-term prognosis in CAD patients with pre-DM undergoing $\mathrm{PCl}$, and indicated a joint prognostic value of FIB levels and impaired glycemic metabolism on mortality in CAD patients undergoing $\mathrm{PCl}$.

FIB is a crucial glycoprotein consisting of three different polypeptides, which is mainly synthesized in the liver[15]. Upon action of thrombin, FIB is transformed into fibrin monomer which then crosslinks platelets, increases blood viscosity and ultimately leads to clot formation[3]. Besides, FIB levels are elevated in response to various chronic inflammatory conditions, including DM, obesity and atherosclerosis[7, 12, 16]. It is also directly involved in the pathogenesis of atherosclerosis through multiple mechanisms, such as inducing endothelial dysfunction, stimulating smooth muscle cell proliferation and migration, facilitating monocyte or macrophage adhesion and infiltration of atherosclerotic lesions, which will jointly potentiate plaque evolution[17].

To date, studies have been conducted on the prognostic value of FIB in different clinical settings. Aside from the positive association with all-cause and CVD mortality in general individuals[6, 18, 19], FIB was reported to be an independent risk factor of the occurrence and severity of $C A D[20]$. Further, both small sample and large epidemiological studies showed that FIB was associated with worse clinical outcomes in patients with stable $C A D[10,21,22]$. A recent prospective study from China indicated elevated FIB was also strongly associated with MACE risk in ACS patients, especially when complicated with DM[9]. Similarly, the present study found FIB had an independent association with long-term all-cause and cardiac mortality in CAD patients undergoing PCI. Instead, the ADVANCE study showed FIB was not an independent predictor of macrovascular events and mortality in diabetic patients with documented CVD or risk factors[23]. The PRIME study and the EPIC-Norfolk study found FIB was not a long-term predictor of all-cause or cardiovascular mortality in subjects free of $\mathrm{CAD}[24,25]$. The controversial results may result from the heterogeneity of the study population. In spite of the conflicting findings mentioned above, data from the latest clinical trials confirmed the benefit of anti-inflammatory effect both in patients with chronic coronary disease and acute $\mathrm{MI}[26,27]$. Considering the role of FIB as an inflammatory biomarker, additional studies are warranted to further evaluate whether FIB could be helpful to identify high-risk individuals in CAD patients.

Currently, glycemic metabolism abnormality including DM and pre-DM is prevalent in clinical practice, especially in patients with established CAD [11]. It has been previously demonstrated that DM independently increased the risk of adverse CVD events in CAD patients[28]. Notably, CAD patients with pre-DM seemed to share similar clinical outcomes with those with normoglycemia[10, 29]. However, when combined with other disorders, such as dyslipidemia or hypertension, prediabetic patients with CAD were demonstrated to have significantly less favorable prognosis[30-32]. Interestingly, a large-sample 
observational study recently reported that elevated FIB increased the MACE risk in patients with stable $C A D$ only in the presence of $D M$ and pre-DM, indicating FIB to be valuable for prognostic assessment in prediabetic patients with stable CAD[10]. However, the combined value of FIB and impaired glycemic metabolism on prediction of mortality in CAD patients undergoing $\mathrm{PCl}$ is still unclear. In this study, we observed that among CAD patients undergoing $\mathrm{PCl}$, diabetic individuals with high or medium FIB levels had 2.57-fold and 3.04-fold higher risk of mortality respectively during a median follow-up of 5.1 years. Furthermore, prediabetic patients also had higher mortality risk in the subgroup of high FIB levels, indicating that FIB may be useful for further risk stratification in CAD patients with mild impaired glycemic metabolism after PCl.

Patients with DM were confirmed to have higher levels of plasma FIB[12]. Chronic mild inflammation is a recognized pathological mechanism of DM[33]. Elevated FIB existing in diabetic patients aggravates the inflammatory process and the burden of atherosclerosis[4,34]. FIB also involves in insulin resistance and impair the normal glycemic regulation[13]. Moreover, elevated FIB could weaken platelet inhibition with clopidogrel in the presence of DM[35]. And this effect is mediated through its direct interaction with the GP IIb/Illa receptor, which is independent from inflammation. Indeed, our study found that the average levels of FIB elevated from NG, pre-DM to DM. Moreover, FIB was also positively associated with glycemic metabolism (HbA1c and FBG) both in CAD patients with or without DM, which was basically consistent with the prior studies $[9,10]$. Collectively, although without established causality, the present study revealed a robust association between FIB and glycemic metabolism, as well as the long-term mortality in CAD patients undergoing PCl. Given the relatively simple and cost-effective test of FIB, these findings encourage its potential value as a biomarker in this specific population to identify high-risk patients, especially in those with DM and pre-DM. Meanwhile, the importance of routine screening for impaired glycemic metabolism also cannot be neglected. In addition, whether this specific population could benefit from lowering FIB levels through lifestyle modification or pharmacologic intervention warrants future studies.

This study has some limitations. First, FIB test was only performed at baseline. Data on FIB level fluctuation during follow-up was not available. Second, due to the observational design, potential confounders cannot be fully controlled. Third, a direct causal link between FIB and mortality risk was not established by this study.

\section{Conclusions}

FIB was strongly associated with long-term all-cause and cardiac mortality among CAD patients undergoing $\mathrm{PCl}$, especially in those with $\mathrm{DM}$ and Pre-DM. FIB test may help to identify high-risk individuals in this specific population.

\section{Abbreviations}


FIB: Fibrinogen; CAD: Coronary artery disease; PCl: Percutaneous coronary intervention; DM: Diabetes mellitus; Pre-DM: Prediabetes; NG: Normoglycemia; HbA1c: Hemoglobin A1c; FBG: Fasting blood glucose; CVD: Cardiovascular disease; ACS: Acute coronary syndrome; LDL-C: Low-density lipoprotein cholesterol; Cl: Confidence interval; BMI: Body mass index; CABG: Coronary artery bypass grafting; LVEF: Left ventricular ejection fraction; DES: Drug-eluting stent; ACEl: Angiotensin-converting enzyme inhibitors; ARB: Angiotensin II receptor blockers; TC: Total cholesterol; TG: Triglycerides; HDL-C: High-density lipoprotein cholesterol; MACE: Major adverse cardiovascular events; MI: Myocardial infarction.

\section{Declarations}

\section{Ethics approval and consent to participate}

The Ethical Review Board of Fuwai Hospital approved the study protocol in accordance with the Declaration of Helsinki, and written informed consent was obtained from all participants.

\section{Consent for publication}

The manuscript was approved by all authors for publication.

\section{Availability of data and materials}

Due to ethical restrictions related to the consent given by subjects at the time of study commencement, our datasets are available from the corresponding author upon reasonable request after permission of the Institutional Review Board of Fuwai Hospital.

\section{Competing interests}

All authors declare that they have no competing interests.

\section{Funding}

This work was supported by The National Key Research and Development Program of China (No. 2016YFC1301300, 2016YFC1301301); National Natural Science Foundation of China (No. 81770365).

\section{Author contributions}

YDS, ZXY, GRL, YYJ, XB, GZ and YJQ contributed to the conception and design of the work. JP, ZP, JSD, ZC, LY, LR, XJJ and TXF contributed to in data collection and analysis. YDS drafted the manuscript. YJQ critically revised the manuscript. All authors read and approved the final manuscript.

\section{Acknowledgements}

We are grateful to all staff members for their contribution to the study. 


\section{References}

1. Koskinas KC, Siontis GCM, Piccolo R, Franzone A, Haynes A, Rat-Wirtzler J, Silber S, Serruys PW, Pilgrim T, Räber L, et al. Impact of Diabetic Status on Outcomes After Revascularization With DrugEluting Stents in Relation to Coronary Artery Disease Complexity: Patient-Level Pooled Analysis of 6081 Patients. Circ Cardiovasc Interv. 2016;9(2):e003255.

2. Lowe GD. Fibrinogen and cardiovascular disease: historical introduction. Eur Heart J. 1995;16 Suppl A:2-5.

3. Danesh J, Collins R, Peto R, Lowe GD. Haematocrit, viscosity, erythrocyte sedimentation rate: metaanalyses of prospective studies of coronary heart disease. Eur Heart J. 2000;21(7):515-20.

4. Espinola-Klein C, Rupprecht HJ, Bickel C, Lackner K, Schnabel R, Munzel T, Blankenberg S. Inflammation, atherosclerotic burden and cardiovascular prognosis. Atherosclerosis. 2007;195(2):e126-34.

5. Smith EB: Fibrinogen, fibrin and the arterial wall. Eur Heart J 1995, 16 Suppl A.

6. Danesh J, Lewington S, Thompson SG, Lowe GDO, Collins R, Kostis JB, Wilson AC, Folsom AR, Wu K, Benderly $\mathrm{M}$, et al. Plasma fibrinogen level and the risk of major cardiovascular diseases and nonvascular mortality: an individual participant meta-analysis. JAMA. 2005;294(14):1799-809.

7. Stec JJ, Silbershatz H, Tofler GH, Matheney TH, Sutherland P, Lipinska I, Massaro JM, Wilson PF, Muller JE, D'Agostino RB. Association of fibrinogen with cardiovascular risk factors and cardiovascular disease in the Framingham Offspring Population. Circulation. 2000;102(14):1634-8.

8. Ang L, Behnamfar O, Palakodeti S, Lin F, Pourdjabbar A, Patel MP, Reeves RR, Mahmud E. Elevated Baseline Serum Fibrinogen: Effect on 2-Year Major Adverse Cardiovascular Events Following Percutaneous Coronary Intervention. J Am Heart Assoc 2017, 6(11).

9. Zhang L, Xu C, Liu J, Bai X, Li R, Wang L, Zhou J, Wu Y, Yuan Z. Baseline plasma fibrinogen is associated with haemoglobin A1c and 2-year major adverse cardiovascular events following percutaneous coronary intervention in patients with acute coronary syndrome: a single-centre, prospective cohort study. Cardiovasc Diabetol. 2019;18(1):52.

10. Liu S-L, Wu N-Q, Shi H-W, Dong Q, Dong Q-T, Gao Y, Guo Y-L, Li J-J. Fibrinogen is associated with glucose metabolism and cardiovascular outcomes in patients with coronary artery disease. Cardiovasc Diabetol. 2020;19(1):36.

11. Cho NH, Shaw JE, Karuranga S, Huang Y, da Rocha Fernandes JD, Ohlrogge AW, Malanda B. IDF Diabetes Atlas: Global estimates of diabetes prevalence for 2017 and projections for 2045. Diabetes Res Clin Pract. 2018;138:271-81.

12. Barazzoni R, Zanetti M, Davanzo G, Kiwanuka E, Carraro P, Tiengo A, Tessari P. Increased fibrinogen production in type 2 diabetic patients without detectable vascular complications: correlation with plasma glucagon concentrations. J Clin Endocrinol Metab. 2000;85(9):3121-5.

13. Kristiansen OP, Mandrup-Poulsen T. Interleukin- 6 and diabetes: the good, the bad, or the indifferent? Diabetes 2005, 54Suppl 2:S114-S124. 
14. 2. Classification and Diagnosis of Diabetes. Diabetes Care 2019, 42(Suppl 1):S13-S28.

15. Tousoulis D, Papageorgiou N, Androulakis E, Briasoulis A, Antoniades C, Stefanadis C. Fibrinogen and cardiovascular disease: genetics and biomarkers. Blood Rev. 2011;25(6):239-45.

16. Bäck M, Yurdagul A, Tabas I, Öörni K, Kovanen PT. Inflammation and its resolution in atherosclerosis: mediators and therapeutic opportunities. Nat Rev Cardiol. 2019;16(7):389-406.

17. Green D, Foiles N, Chan C, Schreiner PJ, Liu K. Elevated fibrinogen levels and subsequent subclinical atherosclerosis: the CARDIA Study. Atherosclerosis. 2009;202(2):623-31.

18. Yano K, Grove JS, Chen R, Rodriguez BL, Curb JD, Tracy RP. Plasma fibrinogen as a predictor of total and cause-specific mortality in elderly Japanese-American men. Arterioscler Thromb Vasc Biol. 2001;21(6):1065-70.

19. Jenny NS, Yanez ND, Psaty BM, Kuller LH, Hirsch CH, Tracy RP. Inflammation biomarkers and nearterm death in older men. Am J Epidemiol. 2007;165(6):684-95.

20. Kaptoge S, Di Angelantonio E, Pennells L, Wood AM, White IR, Gao P, Walker M, Thompson A, Sarwar $\mathrm{N}$, Caslake $\mathrm{M}$, et al. C-reactive protein, fibrinogen, and cardiovascular disease prediction. $\mathrm{N}$ Engl J Med. 2012;367(14):1310-20.

21. Sinning J-M, Bickel C, Messow C-M, Schnabel R, Lubos E, Rupprecht HJ, Espinola-Klein C, Lackner KJ, Tiret L, Münzel T, et al. Impact of $C$-reactive protein and fibrinogen on cardiovascular prognosis in patients with stable angina pectoris: the AtheroGene study. Eur Heart J. 2006;27(24):2962-8.

22. Mjelva $\varnothing R$, Svingen GFT, Pedersen EKR, Seifert R, Kvaløy JT, Midttun $\emptyset$, Ueland PM, Nordrehaug JE, Nygård O, Nilsen DWT. Fibrinogen and Neopterin Is Associated with Future Myocardial Infarction and Total Mortality in Patients with Stable Coronary Artery Disease. Thromb Haemost. 2018;118(4):77890.

23. Lowe G, Woodward M, Hillis G, Rumley A, Li Q, Harrap S, Marre M, Hamet P, Patel A, Poulter N, et al. Circulating inflammatory markers and the risk of vascular complications and mortality in people with type 2 diabetes and cardiovascular disease or risk factors: the ADVANCE study. Diabetes. 2014;63(3):1115-23.

24. Luc G, Bard J-M, Juhan-Vague I, Ferrieres J, Evans A, Amouyel P, Arveiler D, Fruchart J-C, Ducimetiere P. C-reactive protein, interleukin- 6 , and fibrinogen as predictors of coronary heart disease: the PRIME Study. Arterioscler Thromb Vasc Biol. 2003;23(7):1255-61.

25. Ahmadi-Abhari S, Luben RN, Wareham NJ, Khaw K-T. Seventeen year risk of all-cause and causespecific mortality associated with C-reactive protein, fibrinogen and leukocyte count in men and women: the EPIC-Norfolk study. Eur J Epidemiol. 2013;28(7):541-50.

26. Tardif J-C, Kouz S, Waters DD, Bertrand OF, Diaz R, Maggioni AP, Pinto FJ, Ibrahim R, Gamra H, Kiwan GS, et al. Efficacy and Safety of Low-Dose Colchicine after Myocardial Infarction. N Engl J Med. 2019;381(26):2497-505.

27. Nidorf SM, Fiolet ATL, Mosterd A, Eikelboom JW, Schut A, Opstal TSJ, The SHK, Xu X-F, Ireland MA, Lenderink $\mathrm{T}$, et al. Colchicine in Patients with Chronic Coronary Disease. N Engl J Med. 2020;383(19):1838-47. 
28. Haffner SM, Lehto S, Rönnemaa T, Pyörälä K, Laakso M. Mortality from coronary heart disease in subjects with type 2 diabetes and in nondiabetic subjects with and without prior myocardial infarction. N Engl J Med. 1998;339(4):229-34.

29. Yuan D, Zhang C, Jia S, Jiang L, Xu L, Zhang Y, Xu J, Xu B, Hui R, Gao R, et al. Prediabetes and longterm outcomes in patients with three-vessel coronary artery disease: A large single-center cohort study. J Diabetes Investig. 2021;12(3):409-16.

30. Jin J-L, Cao Y-X, Zhang H-W, Sun D, Hua Q, Li Y-F, Guo Y-L, Wu N-Q, Zhu C-G, Gao Y, et al. Lipoprotein(a) and Cardiovascular Outcomes in Patients With Coronary Artery Disease and Prediabetes or Diabetes. Diabetes Care. 2019;42(7):1312-8.

31. Jin J-L, Zhang H-W, Cao Y-X, Liu H-H, Hua Q, Li Y-F, Zhang Y, Guo Y-L, Wu N-Q, Zhu C-G, et al. Longterm prognostic utility of low-density lipoprotein (LDL) triglyceride in real-world patients with coronary artery disease and diabetes or prediabetes. Cardiovasc Diabetol. 2020;19(1):152.

32. Liu H-H, Cao Y-X, Li S, Guo Y-L, Zhu C-G, Wu N-Q, Gao Y, Dong Q-T, Zhao X, Zhang Y, et al. Impacts of Prediabetes Mellitus Alone or Plus Hypertension on the Coronary Severity and Cardiovascular Outcomes. Hypertension. 2018;71(6):1039-46.

33. Odegaard AO, Jacobs DR, Sanchez OA, Goff DC, Reiner AP, Gross MD. Oxidative stress, inflammation, endothelial dysfunction and incidence of type 2 diabetes. Cardiovasc Diabetol. 2016;15:51.

34. Yahagi K, Kolodgie FD, Lutter C, Mori H, Romero ME, Finn AV, Virmani R. Pathology of Human Coronary and Carotid Artery Atherosclerosis and Vascular Calcification in Diabetes Mellitus. Arterioscler Thromb Vasc Biol. 2017;37(2):191-204.

35. Ang L, Palakodeti V, Khalid A, Tsimikas S, Idrees Z, Tran P, Clopton P, Zafar N, Bromberg-Marin G, Keramati $S$, et al. Elevated plasma fibrinogen and diabetes mellitus are associated with lower inhibition of platelet reactivity with clopidogrel. J Am Coll Cardiol. 2008;52(13):1052-9.

\section{Tables}

Table 1 Baseline characteristics for patients with different FIB levels 


\begin{tabular}{|c|c|c|c|c|c|}
\hline Variables & $\begin{array}{l}\text { Total } \\
(n=6140)\end{array}$ & $\begin{array}{l}\text { FIB-L } \\
\text { In=2069区 }\end{array}$ & $\begin{array}{l}\text { FIB-M } \\
\text { Øn=2033】 }\end{array}$ & $\begin{array}{l}\text { FIB-H } \\
\text { Øn=2038区 }\end{array}$ & $P$ value \\
\hline Age, years & $58.4 \pm 10.4$ & $57.3 \pm 10.2$ & $58.2 \pm 10.2$ & $59.6 \pm 10.6$ & $₫ 0.001$ \\
\hline Male, \% & $\begin{array}{l}4771 \\
(77.7)\end{array}$ & 1729ه83.6ه & 1567ه77.1区 & $1475 \bigotimes 72.4 \rrbracket$ & $₫ 0.001$ \\
\hline $\mathrm{BMI}, \mathrm{kg} / \mathrm{m}^{2}$ & $25.9 \pm 3.2$ & $25.7 \pm 3.1$ & $26.1 \pm 3.2$ & $25.9 \pm 3.3$ & $\varangle 0.001$ \\
\hline Diabetes mellitus, \% & $\begin{array}{l}1862 \\
(30.3)\end{array}$ & $521 \rrbracket 25.2 \rrbracket$ & $656 \rrbracket 32.3 \rrbracket$ & 685『33.6》 & $\otimes 0.001$ \\
\hline Hypertension, \% & $\begin{array}{l}3930 \\
(64.0)\end{array}$ & 1248囚60.3凶 & $1328 \otimes 65.3 \rrbracket$ & 1354囚66.4】 & $\otimes 0.001$ \\
\hline Dyslipidemia, \% & $\begin{array}{l}4241 \\
(69.1)\end{array}$ & 1403囚67.8ه & 1436冈70.6冈 & 1402ه68.8\ & 0.140 \\
\hline Family history of CAD, \% & $\begin{array}{l}1433 \\
(23.3)\end{array}$ & $501 \rrbracket 24.2 \rrbracket$ & $479 \llbracket 23.6 \rrbracket$ & $453 \llbracket 22.2 \rrbracket$ & 0.309 \\
\hline Smoking, \% & $\begin{array}{l}3496 \\
(56.9)\end{array}$ & 1197凶57.9凶 & 1173ه57.7凶 & 1126冈55.3囚 & 0.169 \\
\hline Prior MI, \% & $\begin{array}{l}1219 \\
(19.9)\end{array}$ & $465 \rrbracket 22.5 \rrbracket$ & 394囚19.4】 & 360®17.7》 & $₫ 0.001$ \\
\hline Prior PCl or CABG, \% & $\begin{array}{l}1581 \\
(25.7)\end{array}$ & $621 \rrbracket 30.0 \rrbracket$ & $514 \llbracket 25.3 \rrbracket$ & $446 \rrbracket 21.9 \rrbracket$ & $\otimes 0.001$ \\
\hline Prior stroke, \% & $658(10.7)$ & $204 \rrbracket 9.9 \rrbracket$ & 206ه10.1区 & $248 \otimes 12.2 \rrbracket$ & 0.033 \\
\hline Clinical presentation, \% & & & & & $\nabla 0.001$ \\
\hline SAP & $\begin{array}{l}2572 \\
(41.9)\end{array}$ & $995(48.1)$ & $874(43.0)$ & 703 (34.5) & \\
\hline ACS & $\begin{array}{l}3568 \\
(58.1)\end{array}$ & $\begin{array}{l}1074 \\
(51.9)\end{array}$ & $\begin{array}{l}1159 \\
(57.0)\end{array}$ & $\begin{array}{l}1335 \\
(65.5)\end{array}$ & \\
\hline LVEF, \% & $63.0 \pm 7.2$ & $63.6 \pm 6.8$ & $63.5 \pm 6.8$ & $62.0 \pm 7.9$ & $\nabla 0.001$ \\
\hline FBG, mmol/L & $6.1 \pm 2.0$ & $5.8 \pm 1.8$ & $6.1 \pm 2.0$ & $6.3 \pm 2.2$ & $\nabla 0.001$ \\
\hline $\mathrm{HbA} 1 \mathrm{c}, \%$ & $6.6 \pm 1.2$ & $6.4 \pm 1.0$ & $6.6 \pm 1.2$ & $6.8 \pm 1.4$ & $\nabla 0.001$ \\
\hline $\mathrm{FIB}, \mathrm{mg} / \mathrm{dL}$ & $3.40 \pm 0.84$ & $2.62 \pm 0.28$ & $3.26 \pm 0.17$ & $4.32 \pm 0.74$ & $\nabla 0.001$ \\
\hline $\mathrm{TC}, \mathrm{mmol} / \mathrm{L}$ & $4.17 \pm 1.09$ & $4.00 \pm 1.07$ & $4.21 \pm 1.08$ & $4.30 \pm 1.11$ & $\otimes 0.001$ \\
\hline HDL-C, mmol/L & $1.02 \pm 0.28$ & $1.02 \pm 0.27$ & $1.03 \pm 0.28$ & $1.00 \pm 0.28$ & 0.060 \\
\hline LDL-C, mmol/L & $2.48 \pm 0.92$ & $2.34 \pm 0.91$ & $2.50 \pm 0.91$ & $2.59 \pm 0.93$ & $\otimes 0.001$ \\
\hline $\mathrm{TG}, \mathrm{mmol} / \mathrm{L}$ & $1.81 \pm 1.12$ & $1.75 \pm 1.12$ & $1.85 \pm 1.13$ & $1.83 \pm 1.12$ & 0.015 \\
\hline
\end{tabular}




\begin{tabular}{|c|c|c|c|c|c|}
\hline Creatinine $(\mu \mathrm{mol} / \mathrm{L})$ & $75.4 \pm 16.0$ & $74.5 \pm 14.1$ & $74.6 \pm 15.4$ & $77.0 \pm 18.2$ & $\varangle 0.001$ \\
\hline Lesion vessels & $1.4 \pm 0.7$ & $1.4 \pm 0.6$ & $1.4 \pm 0.7$ & $1.5 \pm 0.7$ & $\otimes 0.001$ \\
\hline LM/three-vessel disease, \% & $\begin{array}{l}2773 \\
(45.2)\end{array}$ & $865(41.8)$ & 909 (44.7) & $999(49.0)$ & $\bowtie 0.001$ \\
\hline SYNTAX score ${ }^{a}$ & $12.0 \pm 8.2$ & $11.2 \pm 7.8$ & $11.9 \pm 8.2$ & $12.8 \pm 8.5$ & $\otimes 0.001$ \\
\hline $\begin{array}{l}\text { Complete revascularization, } \\
\%\end{array}$ & $\begin{array}{l}3310 \\
(53.9)\end{array}$ & $\begin{array}{l}1201 \\
(58.0)\end{array}$ & $\begin{array}{l}1090 \\
(53.6)\end{array}$ & $\begin{array}{l}1019 \\
(50.0)\end{array}$ & $\bowtie 0.001$ \\
\hline Number of stents & $1.8 \pm 1.2$ & $1.8 \pm 1.1$ & $1.8 \pm 1.2$ & $1.9 \pm 1.2$ & 0.148 \\
\hline DES implantation, \% & $\begin{array}{l}5778 \\
(94.1)\end{array}$ & $\begin{array}{l}1941 \\
(93.8)\end{array}$ & $\begin{array}{l}1923 \\
(94.6)\end{array}$ & $\begin{array}{l}1914 \\
(93.9)\end{array}$ & 0.520 \\
\hline \multicolumn{6}{|l|}{ Medications at discharge, \% } \\
\hline Aspirin & $\begin{array}{l}6077 \\
(99.0)\end{array}$ & 2051区99.1区 & 2011ه98.9凶 & $2015 \rrbracket 98.9 \rrbracket$ & 0.680 \\
\hline Clopidogrel & $\begin{array}{l}6020 \\
(98.0)\end{array}$ & $2023 \otimes 97.8 \rrbracket$ & 1997ه98.2】 & $2000 \otimes 98.1 \rrbracket$ & 0.542 \\
\hline$\beta$-blocker & $\begin{array}{l}5609 \\
(91.4)\end{array}$ & 1878ه90.8区 & 1868ه91.9凶 & 1863凶91.4区 & 0.443 \\
\hline ACEI/ARB & $\begin{array}{l}3150 \\
(51.3)\end{array}$ & $983 \rrbracket 47.5 \rrbracket$ & 1049ه51.6ه & $1118 \otimes 54.9 \bigotimes$ & $<0.001$ \\
\hline CCB & $\begin{array}{l}2875 \\
(46.8)\end{array}$ & $952 \rrbracket 46.0 \rrbracket$ & $973 \rrbracket 47.9 \rrbracket$ & $950 \rrbracket 46.6 \rrbracket$ & 0.482 \\
\hline Statin & $\begin{array}{l}5923 \\
(96.5)\end{array}$ & 2002ه96.8区 & 1963凶96.6ه & 1958凶96.1区 & 0.473 \\
\hline Nitrate & $\begin{array}{l}5984 \\
(97.5)\end{array}$ & 2021凶97.7凶 & 1981ه97.4】 & 1982ه97.3囚 & 0.683 \\
\hline
\end{tabular}

Values are presented as mean \pm standard deviation or number (\%).

ACEl, angiotensin-converting enzyme inhibitors; ACS, acute coronary syndrome; ARB, angiotensin II receptor blockers; $\mathrm{BMI}$, body mass index; $\mathrm{CAD}$, coronary artery disease; $\mathrm{CABG}$, coronary artery bypass grafting; CCB, calcium channel blocker; DES, drug-eluting stent; FIB, fibrinogen; FBG, fasting blood glucose; HbA1c, Hemoglobin A1c; HDL-C, high-density lipoprotein cholesterol; LDL-C, low-density lipoprotein cholesterol; LM, left main disease; LVEF, left ventricular ejection fraction; MI, myocardial infarction; $\mathrm{PCl}$, percutaneous coronary intervention; SAP, stable angina pectoris; $\mathrm{TC}$, total cholesterol; TG, triglycerides.

${ }^{a}$ Calculated using an online calculator (http://www.syntaxscore.com/) by a dedicated research group blinded to the clinical data. 
Table 2 Baseline characteristics for patients with different glycemic metabolism status 


\begin{tabular}{|c|c|c|c|c|c|}
\hline Variables & $\begin{array}{l}\text { Total } \\
(n=6140)\end{array}$ & $\begin{array}{l}\text { NG } \\
\text { In=1394区 }\end{array}$ & $\begin{array}{l}\text { Pre-DM } \\
\text { पn=2884】 }\end{array}$ & $\begin{array}{l}\text { DM } \\
\text { Dn=1862区 }\end{array}$ & $P$ value \\
\hline Age, years & $58.4 \pm 10.4$ & $55.9 \pm 10.8$ & $58.9 \pm 10.4$ & $59.4 \pm 9.8$ & $\triangle 0.001$ \\
\hline Male, \% & $\begin{array}{l}4771 \\
(77.7)\end{array}$ & $1138 \bowtie 81.6 \rrbracket$ & 2224ه77.1区 & 1409ه75.7凶 & $\varangle 0.001$ \\
\hline BMI, $\mathrm{kg} / \mathrm{m}^{2}$ & $25.9 \pm 3.2$ & $25.7 \pm 3.1$ & $25.8 \pm 3.2$ & $26.2 \pm 3.2$ & $\varangle 0.001$ \\
\hline Hypertension, \% & $\begin{array}{l}3930 \\
(64.0)\end{array}$ & 830ه59.5ه & 1791凶62.1凶 & $1309 \otimes 70.3 \rrbracket$ & $\otimes 0.001$ \\
\hline Dyslipidemia, \% & $\begin{array}{l}4241 \\
(69.1)\end{array}$ & $906 \varangle 65.0 \otimes$ & 1910冈66.2】 & $1425 \otimes 76.5 \rrbracket$ & $\varangle 0.001$ \\
\hline Family history of CAD, \% & $\begin{array}{l}1433 \\
(23.3)\end{array}$ & $355 \rrbracket 25.5 \rrbracket$ & $653 \llbracket 22.6 \rrbracket$ & $425 \llbracket 22.8 \rrbracket$ & 0.101 \\
\hline Smoking, \% & $\begin{array}{l}3496 \\
(56.9)\end{array}$ & $810 \rrbracket 58.1 \rrbracket$ & 1664囚57.7区 & $1022 \varangle 54.9 \rrbracket$ & 0.098 \\
\hline Prior MI, \% & $\begin{array}{l}1219 \\
(19.9)\end{array}$ & 265囚19.0》 & 567囚19.7》 & $387 \rrbracket 20.8 \rrbracket$ & 0.426 \\
\hline Prior $\mathrm{PCl}$ or $\mathrm{CABG}, \%$ & $\begin{array}{l}1581 \\
(25.7)\end{array}$ & $322 \rrbracket 23.1 \rrbracket$ & $729 \llbracket 25.3 \rrbracket$ & $530 \otimes 28.5 \rrbracket$ & 0.002 \\
\hline Prior stroke, \% & $658(10.7)$ & 130冈9.3》 & $279 \rrbracket 9.7 \rrbracket$ & $249 \rrbracket 13.4 \rrbracket$ & $<0.001$ \\
\hline Clinical presentation, \% & & & & & $\varangle 0.001$ \\
\hline SAP & $\begin{array}{l}2572 \\
(41.9)\end{array}$ & $537(38.5)$ & $\begin{array}{l}1193 \\
(41.4)\end{array}$ & $842(45.2)$ & \\
\hline ACS & $\begin{array}{l}3568 \\
(58.1)\end{array}$ & $857(61.5)$ & $\begin{array}{l}1691 \\
(58.6)\end{array}$ & $\begin{array}{l}1020 \\
(54.8)\end{array}$ & \\
\hline LVEF, \% & $63.0 \pm 7.2$ & $63.0 \pm 7.2$ & $63.3 \pm 7.1$ & $62.6 \pm 7.4$ & $\varangle 0.001$ \\
\hline FBG, mmol/L & $6.1 \pm 2.0$ & $4.7 \pm 0.4$ & $5.2 \pm 0.6$ & $7.3 \pm 2.5$ & 0.009 \\
\hline HbA1c, \% & $6.6 \pm 1.2$ & $5.4 \pm 0.2$ & $6.0 \pm 0.2$ & $7.5 \pm 1.3$ & $\varangle 0.001$ \\
\hline $\mathrm{FIB}, \mathrm{mg} / \mathrm{dL}$ & $3.40 \pm 0.84$ & $3.32 \pm 0.85$ & $3.39 \pm 0.85$ & $3.47 \pm 0.82$ & $\varangle 0.001$ \\
\hline $\mathrm{TC}, \mathrm{mmol} / \mathrm{L}$ & $4.17 \pm 1.09$ & $4.18 \pm 1.10$ & $4.21 \pm 1.08$ & $4.10 \pm 1.10$ & 0.004 \\
\hline $\mathrm{HDL}-\mathrm{C}, \mathrm{mmol} / \mathrm{L}$ & $1.02 \pm 0.28$ & $1.01 \pm 0.28$ & $1.04 \pm 0.28$ & $0.99 \pm 0.27$ & $\varangle 0.001$ \\
\hline LDL-C, mmol/L & $2.48 \pm 0.92$ & $2.50 \pm 0.94$ & $2.51 \pm 0.92$ & $2.41 \pm 0.90$ & 0.001 \\
\hline $\mathrm{TG}, \mathrm{mmol} / \mathrm{L}$ & $1.81 \pm 1.12$ & $1.78 \pm 1.09$ & $1.75 \pm 0.94$ & $1.92 \pm 1.37$ & $\nabla 0.001$ \\
\hline Creatinine ( $\mu \mathrm{mol} / \mathrm{L})$ & $75.4 \pm 16.0$ & $75.6 \pm 15.9$ & $75.5 \pm 15.2$ & $75.0 \pm 17.3$ & 0.485 \\
\hline Lesion vessels & $1.4 \pm 0.7$ & $1.4 \pm 0.6$ & $1.4 \pm 0.7$ & $1.5 \pm 0.7$ & $\varangle 0.001$ \\
\hline
\end{tabular}




\begin{tabular}{|c|c|c|c|c|c|}
\hline LM/three-vessel disease, \% & $\begin{array}{l}2773 \\
(45.2)\end{array}$ & $567(40.7)$ & $\begin{array}{l}1224 \\
(42.4)\end{array}$ & $982(52.7)$ & $₫ 0.001$ \\
\hline SYNTAX score ${ }^{a}$ & $12.0 \pm 8.2$ & $11.7 \pm 7.9$ & $11.7 \pm 8.1$ & $12.6 \pm 8.5$ & 0.001 \\
\hline $\begin{array}{l}\text { Complete revascularization, } \\
\%\end{array}$ & $\begin{array}{l}3310 \\
(53.9)\end{array}$ & 798 (57.2) & $\begin{array}{l}1646 \\
(57.1)\end{array}$ & $866(46.5)$ & $₫ 0.001$ \\
\hline Number of stents & $1.8 \pm 1.2$ & $1.8 \pm 1.1$ & $1.8 \pm 1.1$ & $1.9 \pm 1.3$ & 0.028 \\
\hline DES implantation, \% & $\begin{array}{l}5778 \\
(94.1)\end{array}$ & $\begin{array}{l}1323 \\
(94.9)\end{array}$ & $\begin{array}{l}2730 \\
(94.7)\end{array}$ & $\begin{array}{l}1725 \\
(92.6)\end{array}$ & 0.006 \\
\hline \multicolumn{6}{|l|}{ Medications at discharge, $\%$} \\
\hline Aspirin & $\begin{array}{l}6077 \\
(99.0)\end{array}$ & $1372 \llbracket 98.4 \rrbracket$ & 2859凶99.1区 & 1846ه99.1区 & 0.067 \\
\hline Clopidogrel & $\begin{array}{l}6020 \\
(98.0)\end{array}$ & $1366 \rrbracket 98.0 \rrbracket$ & $2827 \llbracket 98.0 \rrbracket$ & 1827凶98.1区 & 0.959 \\
\hline$\beta$-blocker & $\begin{array}{l}5609 \\
(91.4)\end{array}$ & 1250冈89.7凶 & $2622 \varangle 90.9 \rrbracket$ & 1737凶93.3凶 & 0.001 \\
\hline ACEI/ARB & $\begin{array}{l}3150 \\
(51.3)\end{array}$ & $697 \rrbracket 50.0 \rrbracket$ & 1396ه48.4凶 & $1057 \rrbracket 56.8 \rrbracket$ & $<0.001$ \\
\hline ССВ & $\begin{array}{l}2875 \\
(46.8)\end{array}$ & $604 \rrbracket 43.3 \rrbracket$ & $1341 \otimes 46.5 \rrbracket$ & $930 \rrbracket 49.9 \rrbracket$ & 0.001 \\
\hline Statin & $\begin{array}{l}5923 \\
(96.5)\end{array}$ & 1332ه95.6ه & $2801 \otimes 97.1 \otimes$ & 1790ه96.1ه & 0.022 \\
\hline Nitrate & $\begin{array}{l}5984 \\
(97.5)\end{array}$ & 1358凶97.4凶 & $2820 \otimes 97.8 \rrbracket$ & $1806 \rrbracket 97.0 \rrbracket$ & 0.240 \\
\hline
\end{tabular}

Values are presented as mean \pm standard deviation or number (\%).

ACEl, angiotensin-converting enzyme inhibitors; ACS, acute coronary syndrome; ARB, angiotensin II receptor blockers; $B M I$, body mass index; $C A D$, coronary artery disease; $C A B G$, coronary artery bypass grafting; CCB, calcium channel blocker; DES, drug-eluting stent; DM, diabetes mellitus; FIB, fibrinogen; FBG, fasting blood glucose; HbA1c, Hemoglobin A1c; HDL-C, high-density lipoprotein cholesterol; LDL-C, low-density lipoprotein cholesterol; LM, left main disease; LVEF, left ventricular ejection fraction; MI, myocardial infarction; NG, normoglycemia; PCl, percutaneous coronary intervention; Pre-DM, prediabetes; SAP, stable angina pectoris; TC, total cholesterol; TG, triglycerides.

${ }^{a}$ Calculated using an online calculator (http://www.syntaxscore.com/) by a dedicated research group blinded to the clinical data.

Table 3 Linear regression analysis between glycemic metabolism and FIB in patients with DM, without DM and whole. 


\begin{tabular}{|lllll|}
\hline Variables & Adjusted R2 & Standard $\boldsymbol{\beta}$ & SEM & Pvalue \\
\hline Whole & & & & \\
\hline HbA1c, \% & 0.018 & 0.133 & 0.009 & $<0.001$ \\
\hline FBG, mmol/L & 0.012 & 0.111 & 0.005 & $<0.001$ \\
\hline DM & & & & \\
\hline HbA1c, \% & 0.026 & 0.163 & 0.013 & $<0.001$ \\
\hline FBG, mmol/L & 0.012 & 0.111 & 0.007 & $<0.001$ \\
\hline Non-DM & & & & \\
\hline HbA1c, \% & 0.012 & 0.111 & 0.020 & $<0.001$ \\
\hline FBG, mmol/L & 0.009 & 0.096 & 0.012 & $<0.001$ \\
\hline
\end{tabular}

DM, diabetes mellitus; FBG, fasting blood glucose; FIB, fibrinogen; HbA1c, Hemoglobin A1c; SEM, standard error of estimate

Table 4 Predictive value of the FIB level for all-cause death and cardiac death in univariate and multivariate analysis.

\begin{tabular}{|c|c|c|c|c|c|}
\hline \multirow[t]{2}{*}{ Variables } & \multirow[t]{2}{*}{ Events/Subjects } & \multicolumn{2}{|c|}{ Univariate analysis } & \multicolumn{2}{|c|}{ Multivariate analysis } \\
\hline & & $\begin{array}{l}\text { Hazard ratio } \\
(95 \% \mathrm{Cl})\end{array}$ & $\begin{array}{l}P \\
\text { value }\end{array}$ & $\begin{array}{l}\text { Hazard ratio } \\
(95 \% \mathrm{Cl})\end{array}$ & $\begin{array}{l}P \\
\text { value }\end{array}$ \\
\hline All-cause death & $214 / 6140$ & & & & \\
\hline $\begin{array}{l}\text { FIB (per 1-unit } \\
\text { increase) }\end{array}$ & & $1.36(1.20-1.55)$ & $<0.001$ & $1.23(1.07-1.42)$ & 0.004 \\
\hline FIB-L & $43 / 2069$ & Reference & - & Reference & - \\
\hline FIB-M & $75 / 2033$ & $1.81(1.24-2.63)$ & 0.002 & $1.72(1.18-2.51)$ & 0.005 \\
\hline FIB-H & $96 / 2038$ & $2.35(1.64-3.36)$ & $<0.001$ & $1.86(1.28-2.69)$ & 0.001 \\
\hline Cardiac death & $127 / 6140$ & & & & \\
\hline $\begin{array}{l}\text { FIB (per 1-unit } \\
\text { increase) }\end{array}$ & & $1.46(1.25-1.71)$ & $<0.001$ & $1.31(1.10-1.55)$ & 0.003 \\
\hline FIB-L & $28 / 2069$ & Reference & - & Reference & - \\
\hline FIB-M & $36 / 2033$ & $1.33(0.81-2.18)$ & 0.259 & $1.26(0.76-2.07)$ & 0.369 \\
\hline FIB-H & $63 / 2038$ & $2.36(1.51-3.68)$ & $<0.001$ & $1.82(1.15-2.89)$ & 0.011 \\
\hline
\end{tabular}


Model adjusted for age, sex, BMI, hypertension, diabetes, family history of CAD, prior PCI/CABG, LVEF, LDL-C, creatine, DES implantation, clopidogrel, ACEI/ARB. Cl, confidence interval; FIB fibrinogen.

Table 5 Relation of the FIB level and all-cause death in patients with different glycemic metabolism status.

\begin{tabular}{|llll|}
\hline Variables & Events/Subjects & HR $₫ 95 \%$ CI & \\
\hline NG & $214 / 6140$ & Crude model & Adjusted model \\
\hline FIB-L & $7 / 537$ & Reference & Reference \\
\hline FIB-M & $13 / 433$ & $2.35(0.94-5.87)$ & $2.08(0.83-5.22)$ \\
\hline FIB-H & $14 / 424$ & $2.62(1.06-6.49) *$ & $1.96(0.79-4.89)$ \\
\hline Pre-DM & & & \\
\hline FIB-L & $21 / 1011$ & $1.59(0.68-3.74)$ & $1.24(0.53-2.93)$ \\
\hline FIB-M & $33 / 944$ & $2.73(1.21-6.12) *$ & $2.17(0.96-4.93)$ \\
\hline FIB-H & $40 / 929$ & $3.40(1.52-7.58) * *$ & $2.27(1.01-5.12) *$ \\
\hline DM & & & \\
\hline FIB-L & $15 / 521$ & $2.23(0.91-5.46)$ & $1.67(0.68-4.10)$ \\
\hline FIB-M & $29 / 656$ & $3.45(1.51-7.89) * *$ & $2.57(1.12-5.89) *$ \\
\hline FIB-H & $42 / 685$ & $4.91(2.20-10.92) * *$ & $3.04(1.35-6.82) * *$ \\
\hline
\end{tabular}

Model adjusted for age, sex, BMI, hypertension, diabetes, family history of CAD, prior PCI/CABG, LVEF, LDL-C, creatine, DES implantation, clopidogrel, ACEI/ARB. *P value $<0.05,{ }^{\star *} \mathrm{P}$ value $<0.01$. $\mathrm{Cl}$, confidence interval; FIB, fibrinogen; NG, normoglycemia, Pre-DM, prediabetes; DM, diabetes mellitus.

\section{Figures}




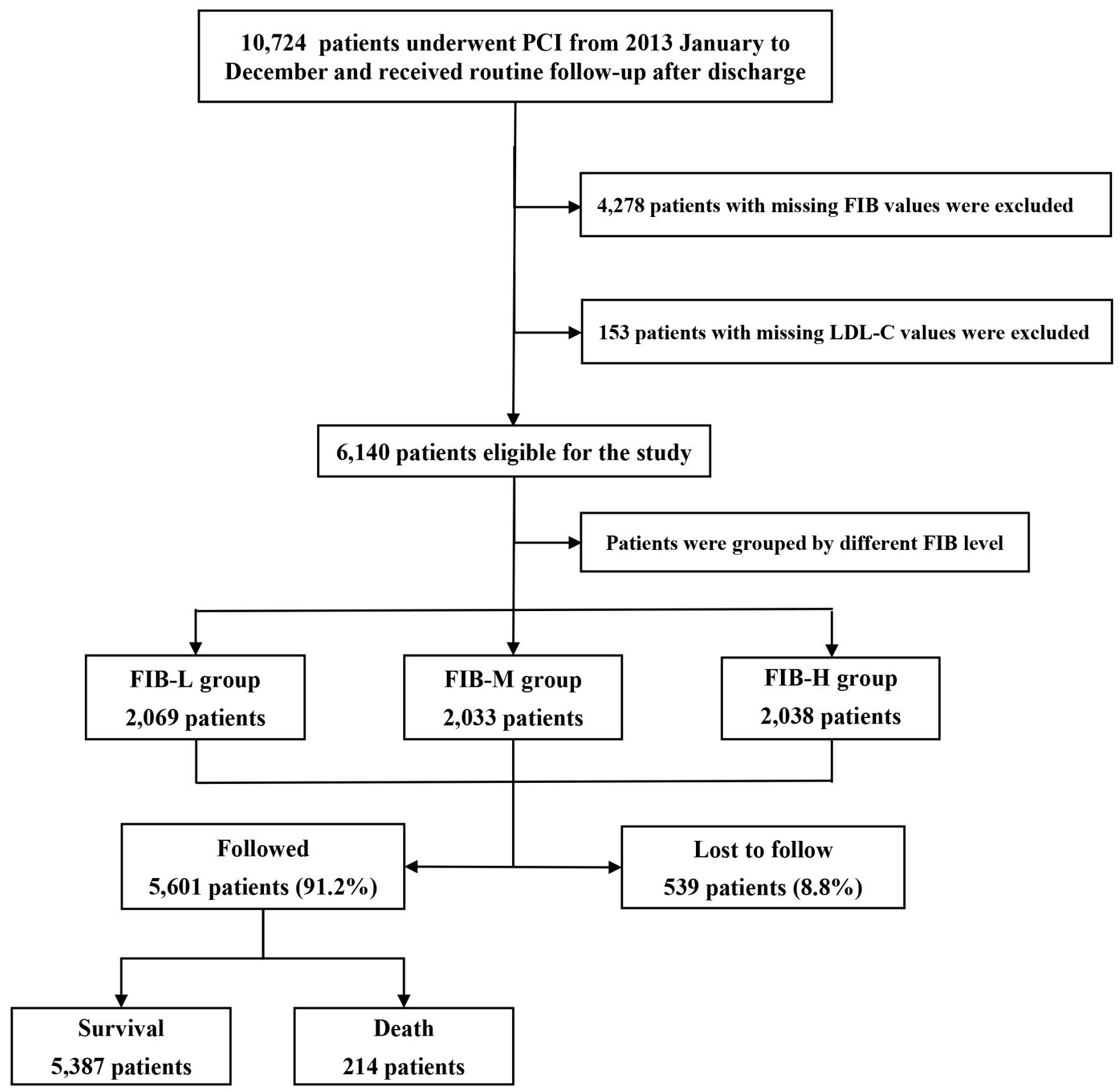

Figure 1

Study flowchart. FIB, fibrinogen, LDL-C, low-density lipoprotein cholesterol, PCl, percutaneous coronary intervention. 

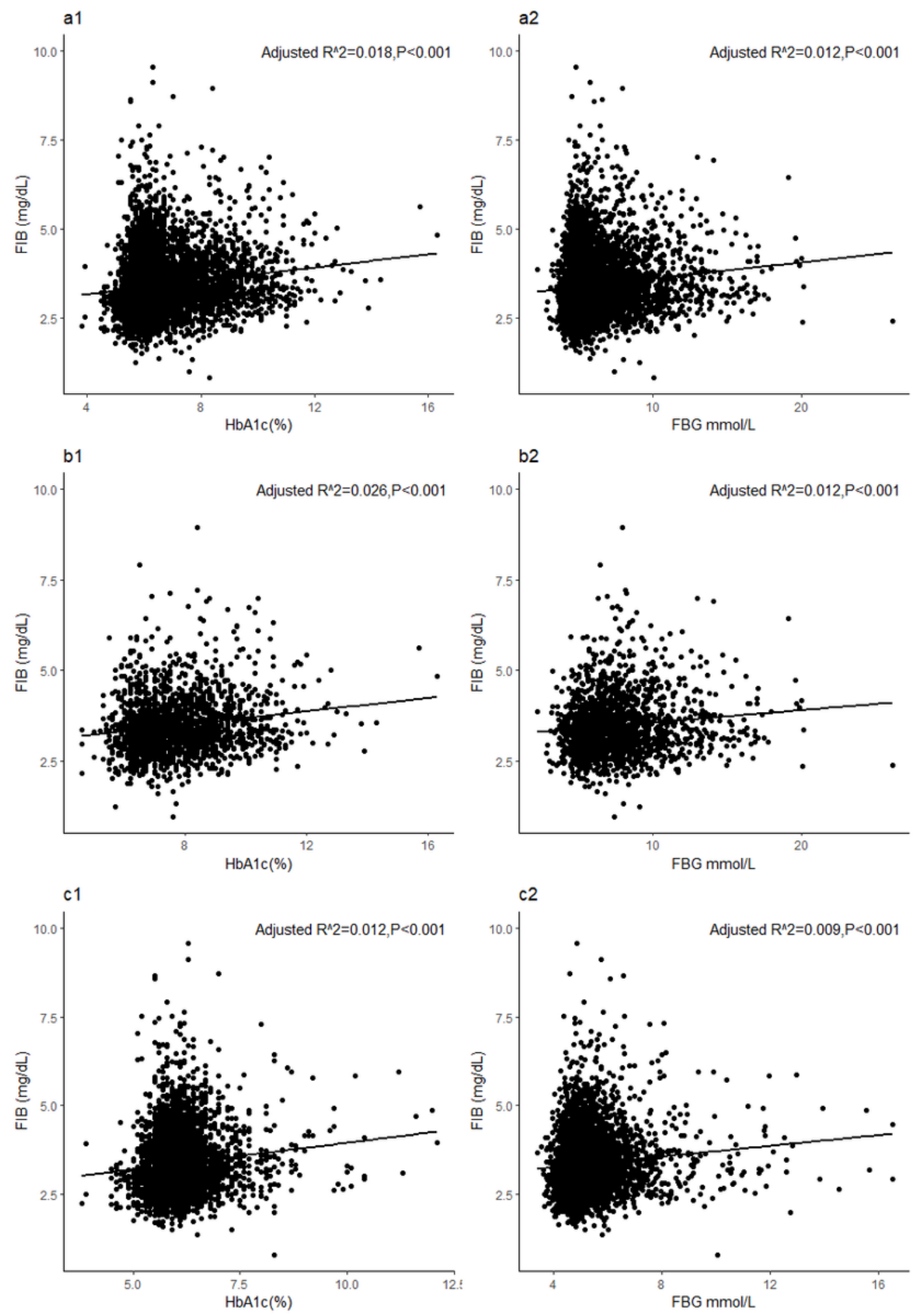

Figure 2

Linear regression analysis of the relationship between glycemic metabolism and FIB. a Linear regression analysis of the relationship between glycemic metabolism (HbA1c and FBG) and FIB in whole patients. $b$ Linear regression analysis of the relationship between glycemic metabolism (HbA1c and FBG) and FIB in patients with DM. c Linear regression analysis of the relationship between glycemic metabolism (HbA1c 
and FBG) and FIB in patients without DM. DM, diabetes mellitus, FBG, fasting blood glucose, FIB, fibrinogen, HbA1c, hemoglobin A1c.

a

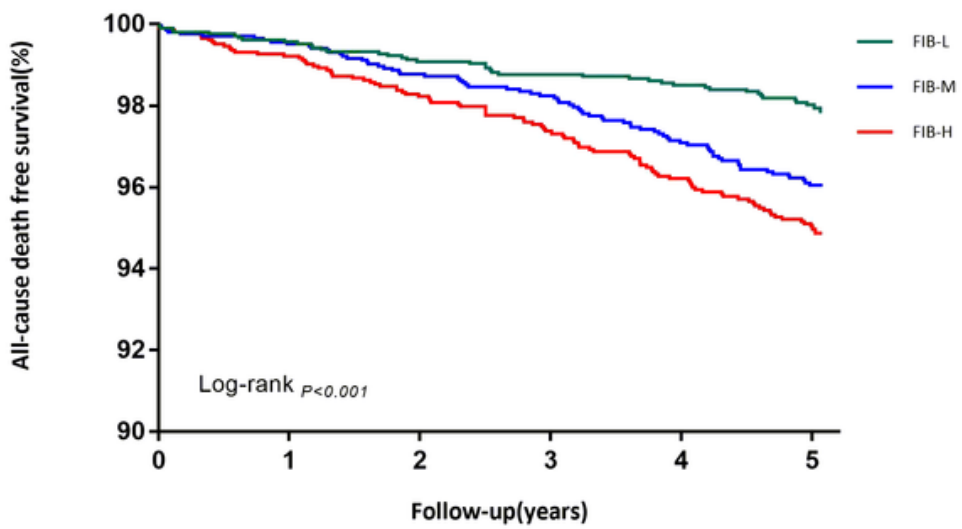

b

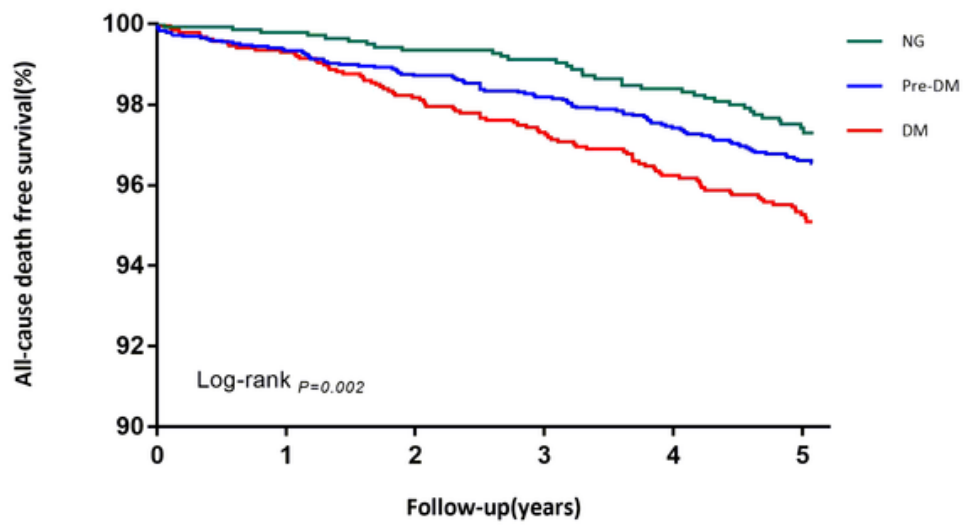

C

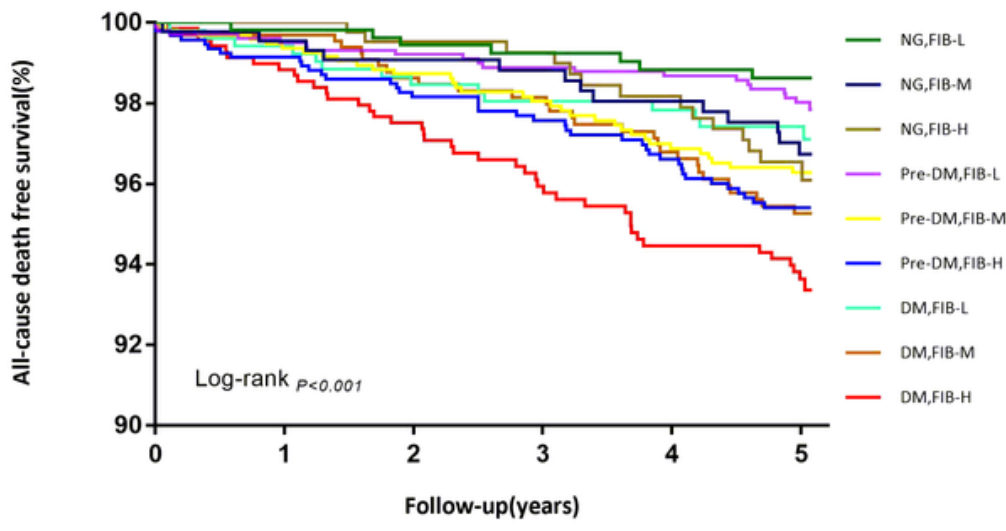

Figure 3

Kaplan-Meier analysis for all-cause death according to different FIB levels (a), glycemic metabolism status (b), and status of both FIB levels and glycemic metabolism (c). 


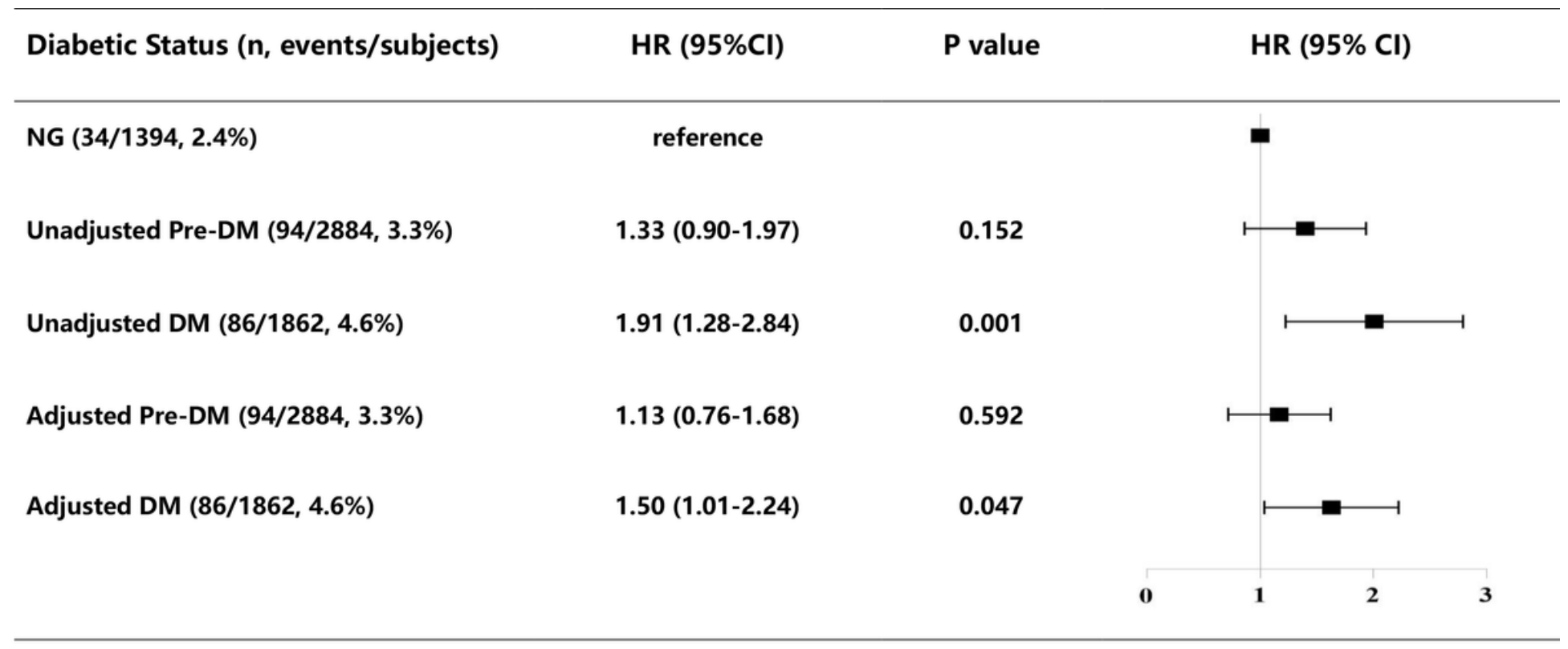

\section{Figure 4}

Relations of different glycemic metabolism status and all-cause death in univariate and multivariate survival analysis. Model adjusted for age, sex, BMI, hypertension, family history of CAD, prior PCI/CABG, LVEF, LDL-C, creatine, DES implantation, clopidogrel, ACEI/ARB. Cl, confidence interval; NG, normoglycemia, Pre-DM, prediabetes; DM, diabetes mellitus.

\section{Supplementary Files}

This is a list of supplementary files associated with this preprint. Click to download.

- Additioonalfile1.docx 